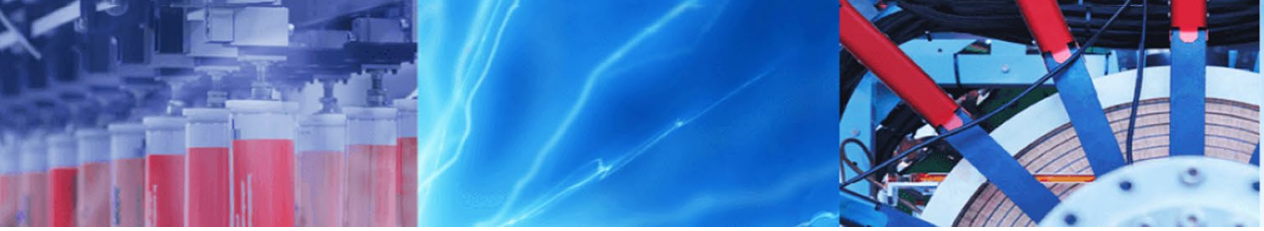

Research Article

\title{
Extracting some soil parameters and estimating elastic settlements from Direct shear box data for a granular C- $\emptyset$ soil
}

\author{
Abidemi Olujide Ilori $^{1}$ \\ (c) Springer Nature Switzerland AG 2019
}

\begin{abstract}
Direct shear box tests were carried out on some soil samples obtained from some locations around Uyo metropolis in Akwa-Ibom State, Southeastern Nigeria. The dominant geology is the Coastal Plain Sands. From the test results, the C- $\varnothing$ properties of the soils were determined. These values were used to compute ultimate and allowable bearing capacities for the soil samples. Elastic, and shear modulus parameters were computed for the different shear values readings for each vertical loading scheme. Poisson ratio was also computed for the same loading scheme applying the elastic relationship between shear modulus and elastic modulus. These parameters were used to compute elastic settlement using the classical elastic theory equation. Two other modified equations of the elastic theory equation and a consolidation equation was also used to compute immediate and consolidation settlements respectively. The values of immediate settlement obtained for the classical elastic equation is less than those computed by the other two modified equations. This is attributed to the fact that the other two equations assumed a constant value of Poisson ratio for the different imposed loads for which computations were made. For the allowable load of $138.54 \mathrm{kPa}$ the classical elastic theory gave an immediate settlement value of $1.02 \mathrm{~cm}$; the other two modified forms of the theory gave values of $2.94 \mathrm{~cm}$ and $4.0 \mathrm{~cm}$. Elastic modulus and Poisson ratio obtained from the Direct shear test for the load are $5662.86 \mathrm{kPa}$ and 0.49 . These values were used in the elastic equation. The same value of $5662.86 \mathrm{kPa}$ was used in the other two modified elastic formulas, but Poisson ratio values of 0.15 and 0.2 were assumed for all loads. Direct shear box test provides a convenient, but plausible means of determining parameters required to compute immediate settlement for the type of soil investigated.
\end{abstract}

Keywords Direct shear box · Elastic modulus · Shear modulus · Poisson ratio · Elastic settlement

\section{Introduction}

The elastic settlement beneath a flexible footing placed on the ground surface is computed as

$S_{e}=\frac{q B\left(1-v^{2}\right) l_{f}}{E}$

where $\mathrm{q}=$ is the surcharge load $(\mathrm{kPa}), \mathrm{B}=$ is the width of the footing $(\mathrm{m}), v=$ Poisson ratio, $l_{f}=$ influence factor, which is a function of ratio of length to width $(L / B)$ and ' $H$ ' which is the thickness of the compressible layer which is often taken at not more than four times the footing width.
In Eq. (1) above, determining the appropriate values of Poisson ratio and the Elastic modulus is often a difficult problem. For the elastic modulus, two methods of determining is value are

1. Laboratory methods

2. Field methods.

For purely cohesionless soil, due to the problem of obtaining undisturbed samples for laboratory use, the laboratory method is not often used. For cohesive soil, triaxial test is

Abidemi Olujide Ilori, bidemiini@gmail.com; abidemiilori@uniuyo.edu.ng | ${ }^{1}$ Department of Civil Engineering, Faculty of Engineering, University of Uyo, Uyo, Akwa Ibom State, Nigeria.

SN Applied Sciences (2019) 1:1309| https://doi.org/10.1007/s42452-019-1347-x

Received: 8 May 2019 / Accepted: 24 September 2019 / Published online: 30 September 2019 
often used with some modifications to take account of consolidation state and sensitivity in case of sensitive soil.

For both cohesive and cohesionless soils the field methods have been found to be reliable. These include,

i. Plate load test (PLT), Standard Penetration Test (SPT) for example [1, 2]

ii. Static Cone Penetration Test (CPT), for example [3]

iii. Pressuremeter Tests (PMT- $[4,5]$

iv. Flat Plate Dilatometer test (DMT, [6, 7]).

v. Geophysical methods (Seismic refraction, spectral analysis of surface waves (SASW) [8], multichannel analysis of surface waves (MASW) [9].

The geophysical method of determination of elastic modulus and Poisson ratio represents small strain methods compared to most laboratory methods. A common laboratory method that is used in determining these parameters is by the use of the Triaxial machine in the Triaxial test. The Triaxial test can be used to determine Poisson ratio for cohesive soils, but not for cohesionless soil because of the difficulty in obtaining undisturbed sample. The Direct shear apparatus as well as the Triaxial device have undergone such a level of refinement, and are now digitalized which allows measurements to a good level of precision that small stress and strain parameters can be measured reliably and accurately. In light of this, this write-up describes how to estimate elastic modulus, Poisson ratio, and computation of elastic settlements from Direct shear box data on $C$ - $\varnothing$ soil from Coastal Plain Sands obtained from some locations around Uyo, Akwa Ibom State, Nigeria.

\section{Study objectives}

The study aims to:

1. Determine the values of cohesion and angle of shearing resistance of soil samples collected.

2. Estimate the Ultimate and allowable bearing resistance of the soil samples,

3. Evaluate elastic modulus, Poisson ratio, shear modulus and other parameters,

4. Estimate elastic settlement using the parameters obtained above.

\section{Materials and method}

\subsection{Soil Index tests}

Block soil samples were collected using the trial pit method from some construction sites where single, two and three storey buildings are being constructed. The block samples were taken at the depth where the foundations of the buildings were placed. From the block samples disturbed and undisturbed tests samples were obtained for soil classification and Direct shear tests. Soil classification tests include;- moisture content, sieve analysis, plastic limit, and liquid limit. These tests were carried out in accordance with relevant American Society of Testing and Materials (ASTM) standards.

\subsection{Direct shear tests}

The direct shear tests were primarily used to determine the $C, \varnothing$ and property of the soils. The digital direct shear machine was model 30-WF6016 T2 (Wykeham Fragrance) attached to a digital data logger which records all parameters automatically during a testing operation and the test were performed in accordance with [10]. The tests were strain controlled. The machine applied strain at the rate of $0.5 \mathrm{~mm}$ per minute. The Direct shear test machine is equipped with strain gauges transducers to measure both horizontal and vertical deformations from the start to the end of the test. It has facility to determine both the peak and residual shear strength of soil, but the latter was not determined for the specimens in this study. Normal load applied to the soil samples were $500 \mathrm{~N}, 1000 \mathrm{~N}$, and $1500 \mathrm{~N}$. Porous plates were placed on top and bottom of the soil sample to allow drainage from soil.

\section{Data analysis}

\subsection{Shear box data}

The Direct shear test device acquires principally three parameters, which are horizontal displacement, vertical displacement and shear force values at regular time during the test. The rest of the parameters are computed. The peak shear and, peak normal stress method [11] were used to determine $C$ - $\varnothing$ property of each sample. For each applied vertical load, a number of computations are made. Computations were carried out with the aid of an excel worksheet. This includes: vertical stress, shear stress, vertical strain, shear strain, 'constrained' modulus, shear modulus, and then Poisson ratio. The latter is computed by applying the relationship

$E=2 G(1+v)$

By imposing the relation given by (2) on the data, it is being assumed that both horizontal and vertical deformation are elastic. Therefore a Poisson ratio values of $-0.5-0.5$ obtained will validate the elastic assumption; whereas 
other values will indicate non-linear and non-elastic situation in the materials

\subsection{Bearing capacity estimates}

Modified Terxaghi bearing capacity equation is used in estimating bearing capacity. The equation is of the form;

$Q_{u}=0.67 c \bar{N}_{c}\left(1+0.3\left(\frac{B}{L}\right)\right)+D_{f} \gamma \bar{N}_{q}+\frac{1}{2} \gamma B \bar{N}_{\gamma}\left(1-0.2\left(\frac{B}{L}\right)\right)$

\subsection{Computations of immediate settlements and consolidation settlement}

In computing immediate settlements, two approaches are used. The first is by using Eq. (1). The second is by [12]. They proposed a method to estimate the elastic settlement which takes into account the variation of the modulus of elasticity of soil with the strain level. This method is also described by [13]. According to the method, elastic settlement is computed using the equation

$\delta_{\text {footing }}=I_{s} \frac{q_{\text {net }}}{E} \mathrm{~B}$

where $\delta_{\text {footing }}=$ elastic settlement, $l_{s}=$ Influence factor for a rigid footing, which depends on the ratio $L / B$ obtained from table given by [14]. In the Table, Poisson ratio is taken to 0.15 , and $I_{s}=0.6$ for the $L / B$ ratio adopted in this study. $\mathrm{E}=$ Modulus of elasticity of the soil.

Consolidation settlements were estimated by using the equation

$S=m_{v} \sigma H$

where $m_{v}=$ is the inverse of one dimensional constrained modulus $(E), \sigma=$ is the imposed load on the soil, which can be safe, allowable or ultimate load that is significantly effective up to the thickness ' $\mathrm{H}$ ', $H=$ is the thickness of compressible stratum where imposed stress value is $0.2 \sigma$ to 0.3 $\sigma$ or $0.8 \mathrm{~B}$ to $1.8 \mathrm{~B}$ [15]. Since ' $\mathrm{B}$ ' used in this study is $2.0 \mathrm{~m}$, ' $\mathrm{H}$ ' translates to $1.2 \mathrm{~m}$ to $3.6 \mathrm{~m}$. $\mathrm{H}=4.0 \mathrm{~m}$ was adopted for computations

In using Eq. (1) to compute elastic settlements the factor $I_{f}$ is defined by the equation

$I_{f}=\left[F_{1}+\frac{\left(1-v-2 v^{2}\right) F_{2}}{\left(1-v^{2}\right)}\right]$

where $F_{1}$ and $F_{2}$ are values from [16] curve and also take on values depending on Poisson ratio values.

If Poisson ratio is $0.5, I_{f}=F_{1}$,

If Poisson ratio is Zero $I_{f}=F_{1}+F_{2}$

If Poisson ratio is between 0 and 0.5 , Eq. (6) is used to calculate $I_{f}$
Equations (1), (4) and (5) were used to estimate settlements in this study

\section{Results and discussion}

\subsection{Soil indices and types}

Table 1 presents some soil indices for the soil samples investigated. Figure 1 presents grain size analysis curves for all the soil samples. The maximum amount passing sieve no 200 for all the samples is $39.82 \%$; making all soil classify as coarse grained soil. The soils are medium to fine grained texture. From Table 1, the soil samples have liquid limit values from 24 to $36 \%$, plastic limit from 13 to $24 \%$, and plasticity index from 8 to $13 \%$. Except for sample 'D' all the soil samples classify as clayey sand (SC), while sample 'D' classifies as clayey sand and silty sand soil (SC-SM). All classification is based on the Unified Soil Classification System (USCS). Compression index (Cc) based on [17] gives values from 0.13 to 0.24

\subsection{C- $\emptyset$ properties and bearing capacities of samples}

Values of cohesion and angle of internal friction determined from Direct shear box ranges from 18.35 to 52.65 $\mathrm{kN} / \mathrm{m}^{2}$ for cohesion, and $23.1^{\circ}$ to $30.74^{\circ}$ for angle of internal friction. Typical Direct shear box data is presented in Fig. 2 for samples ' $D$ ' and ' $E$ '; while Figs. 3 and 4 presents shear stress values versus horizontal deformation for samples $A$ and $B$ respectively.

Due to the numerical values of $C$ and $\varnothing$, the Ultimate bearing capacities values for the soils were computed the using modified Terzaghi bearing capacity equation (Eq. 3 above). Ultimate bearing capacity values ranged from 415.61 to $688.93 \mathrm{kN} / \mathrm{m}^{2}$. Allowable bearing capacity was computed assuming a factor of safety of 3 , and values ranges from 139.39 to $229.64 \mathrm{kN} / \mathrm{m}^{2}$

\subsection{Computations of elastic modulus, shear modulus and Poisson ratio}

For each vertical load sequence, a range of values for vertical strain, shear strain, elastic modulus, shear modulus, and Poisson ratio are calculated. Typical values of these parameters are presented in Tables 2, 3, 4, 5 and 6, for each of the samples whose parameters are employed in settlement computations.

For parameters computed, the early part of the data, usually the first and sometimes the second sets of values are affected by sampling disturbance, and, therefore, may 


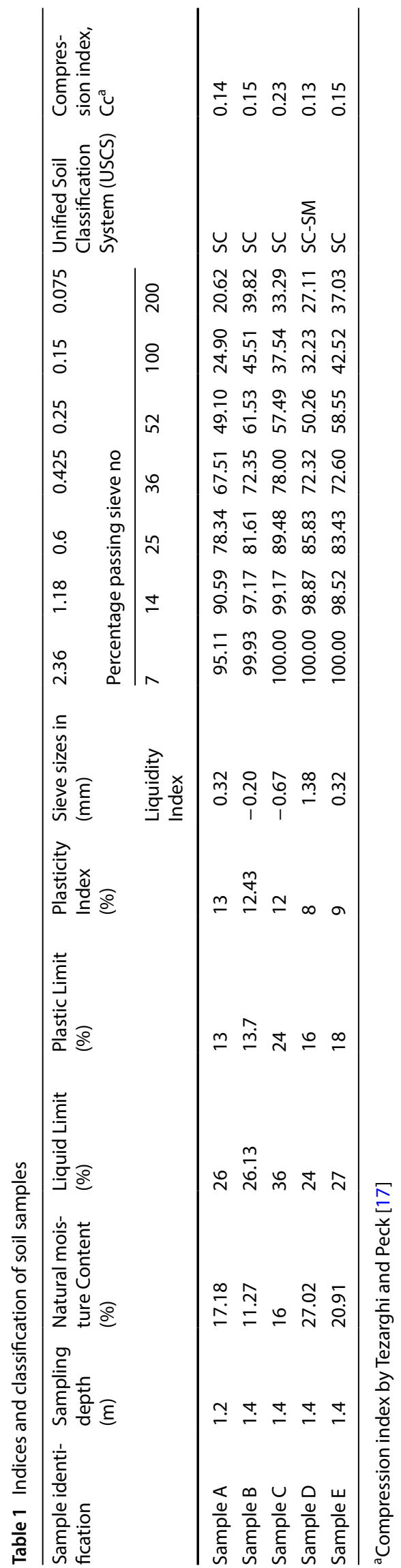

results in parameters estimated in that part of data to be distorted.

Elastic and shear modulus generally decrease with increasing vertical stress. The elastic modulus values are reduced due to the shear stress to which the sample is simultaneously subjected to during the shear tests. Values of elastic modulus obtained, therefore, are conservative. Both parameters are also strain dependent. Typical elastic modulus values used in the computations are from 1484.99 to $6910.45 \mathrm{kPa}$.

Poulos [18] reports that Young's modulus; E can be obtained from the following equations that relates constrained modulus ' $D$ ' with shear modulus ' $G$ '. The equations are $E=3 G /(1+b . G / D)$, where $b=(1-v) /(1+v)$. These equations were also used to compute $E$ in this study, but there is no significant difference between the values obtained and that obtained directly from the shear box test parameters. For example, for samples ' $A$ ' $B$, and $C$, the values of $E$ obtained by these equations are $1466.54 \mathrm{kPa}, 5844.87 \mathrm{kPa}$, and $1989.75 \mathrm{kPa}$ respectively whereas the $\mathrm{E}$ computed from the shear box test data are $1484.99 \mathrm{kPa}, 4112.02 \mathrm{kPa}$, and $2039.41 \mathrm{kPa}$ respectively for the same samples. Furthermore, [19], has stated that for Poisson ratio of zero, constrained modulus is equal to Young's modulus, and that from the works of $[20,21]$ which is about triaxial testing involving small strains, Poisson ratio takes on values from 0.1 to 0.2 at usual working loads such that constrained modulus values takes on $1.05^{\prime} \mathrm{E}^{\prime}$ to $1.11^{\prime} \mathrm{E}$.' Also the modulus derived in the shear box test is not fully constrained; it can be said to be 'partially constrained'. Based on the preceding considerations, the modulus originally estimated from Direct shear box is retained for all computations.

Poisson ratio takes on (if the early part of data are ignored) values that ranges from -0.94 to 4.25 , indicating elastic linear, and nonlinear non-elastic deformation states. In compliance with the elastic theory, Poisson values that indicate linear and elastic values are utilized in the computations of settlement; that is values from -0.5 to +0.5 .

\subsection{Choice of allowable bearing resistance values from direct shear box data}

Parameters associated with values of vertical or normal stress close to the values of allowable bearing resistance computed were adopted in the computation of settlement. The parameters include elastic modulus, and Poisson ratio. The imposed stress, $q$ used was the computed allowable resistance. The values are from 138.54 to $229.64 \mathrm{kPa}$. The vertical stress developed during the Direct shear test may not necessarily have these values, hence the choice of the values closest to the computed allowable 
Fig. 1 Sieve analysis results showing grain size distribution of soil samples used in the study

Fig. 2 Shear stress versus normal stress plot for soil samples 'D' and 'E'
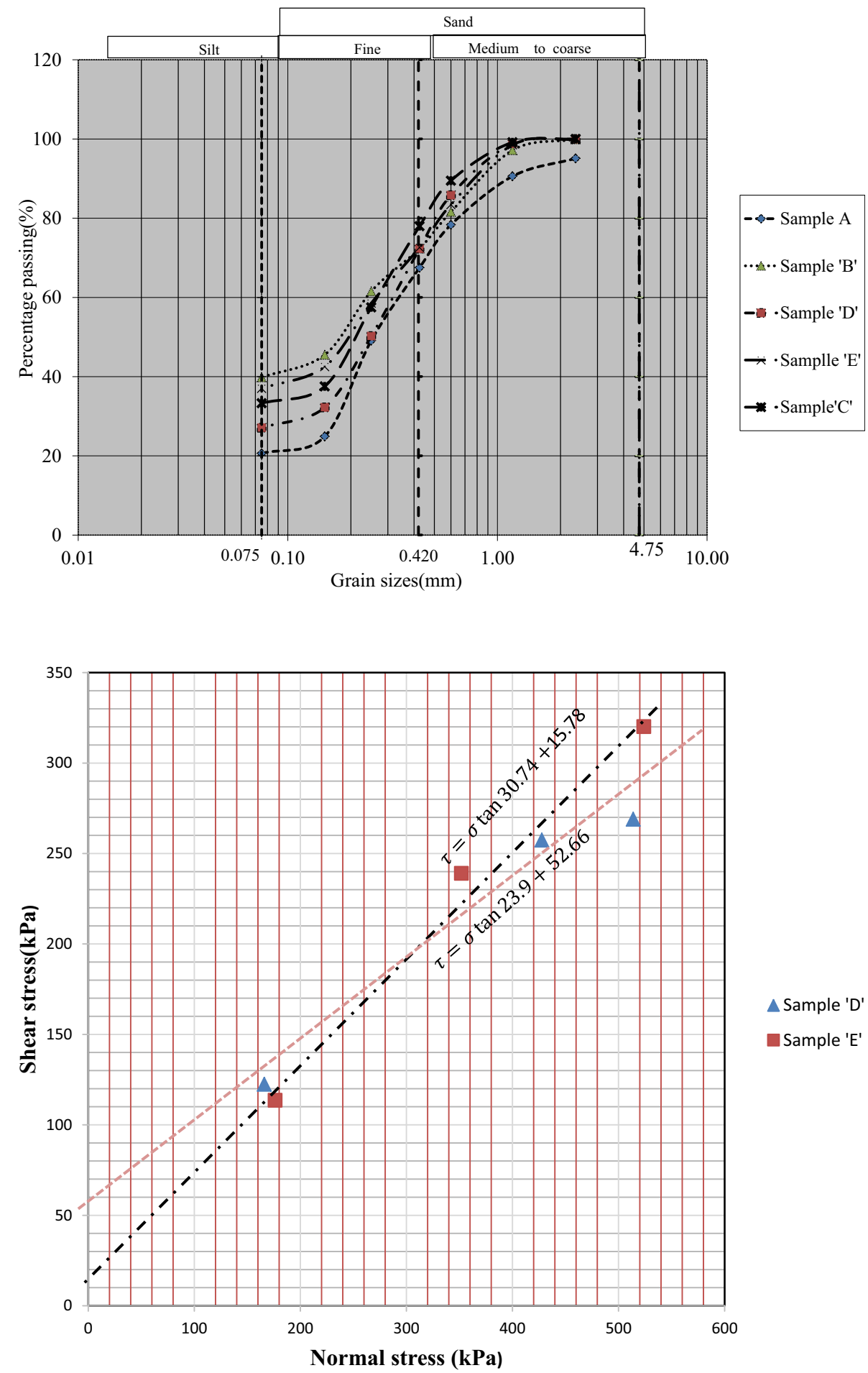

bearing resistance. Vertical stress values after those that give peak shear stress were not selected for computation.

In Foundation engineering practice, it is usual to adopt a factor of safety of three to the ultimate bearing capacity value to obtain the allowable bearing stress. The underlying assumption is that this places the load in the linear elastic region of load-deformation curve. The Poisson ratio values of the allowable bearing stress obtained in this study is between 0.13 and 0.53 . This places the deformation in the soil in the elastic linear range thus asserting the assumption 


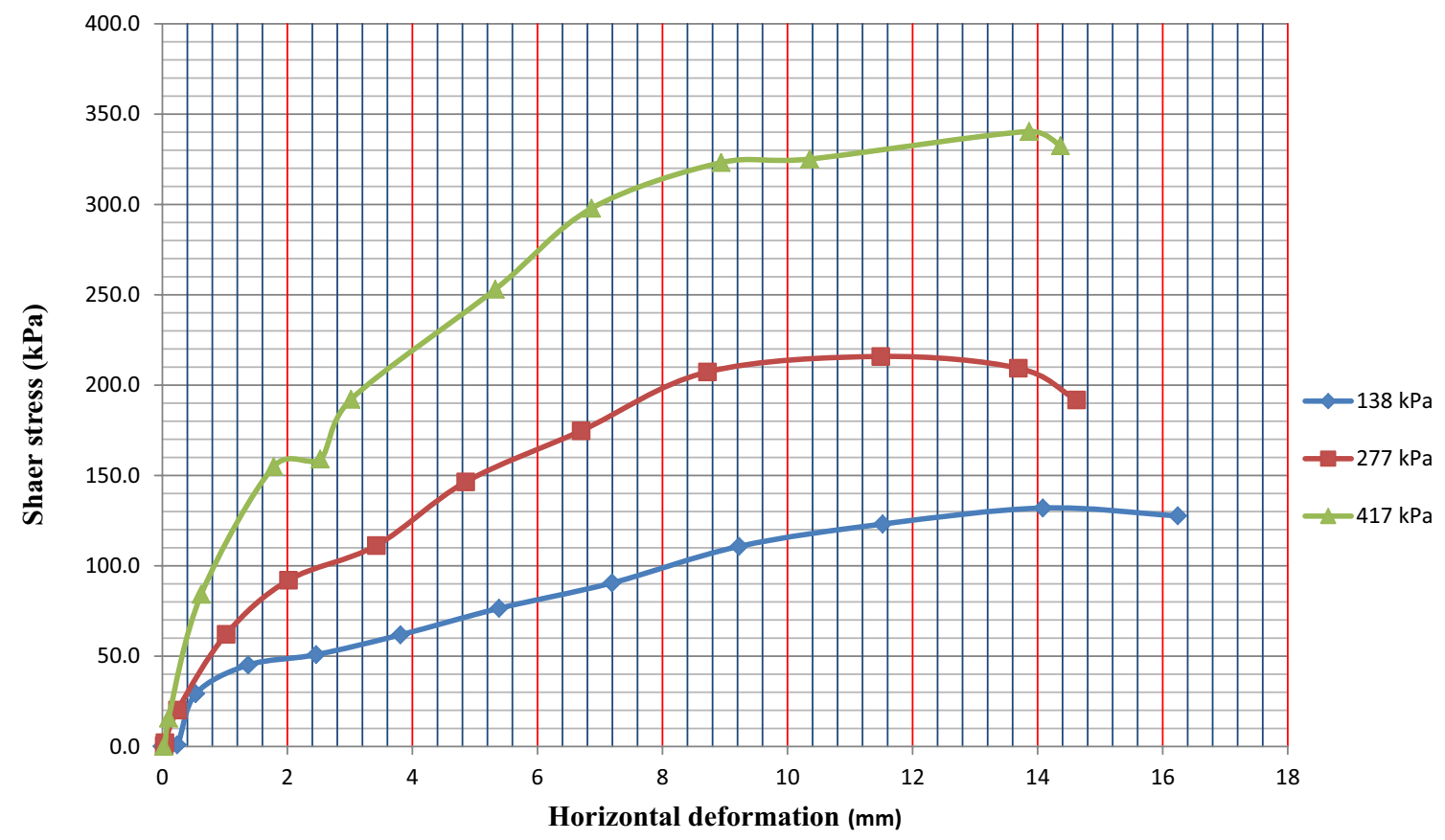

Fig. 3 Shear stress versus horizontal deformation curves for sample ' $\mathrm{A}$ '

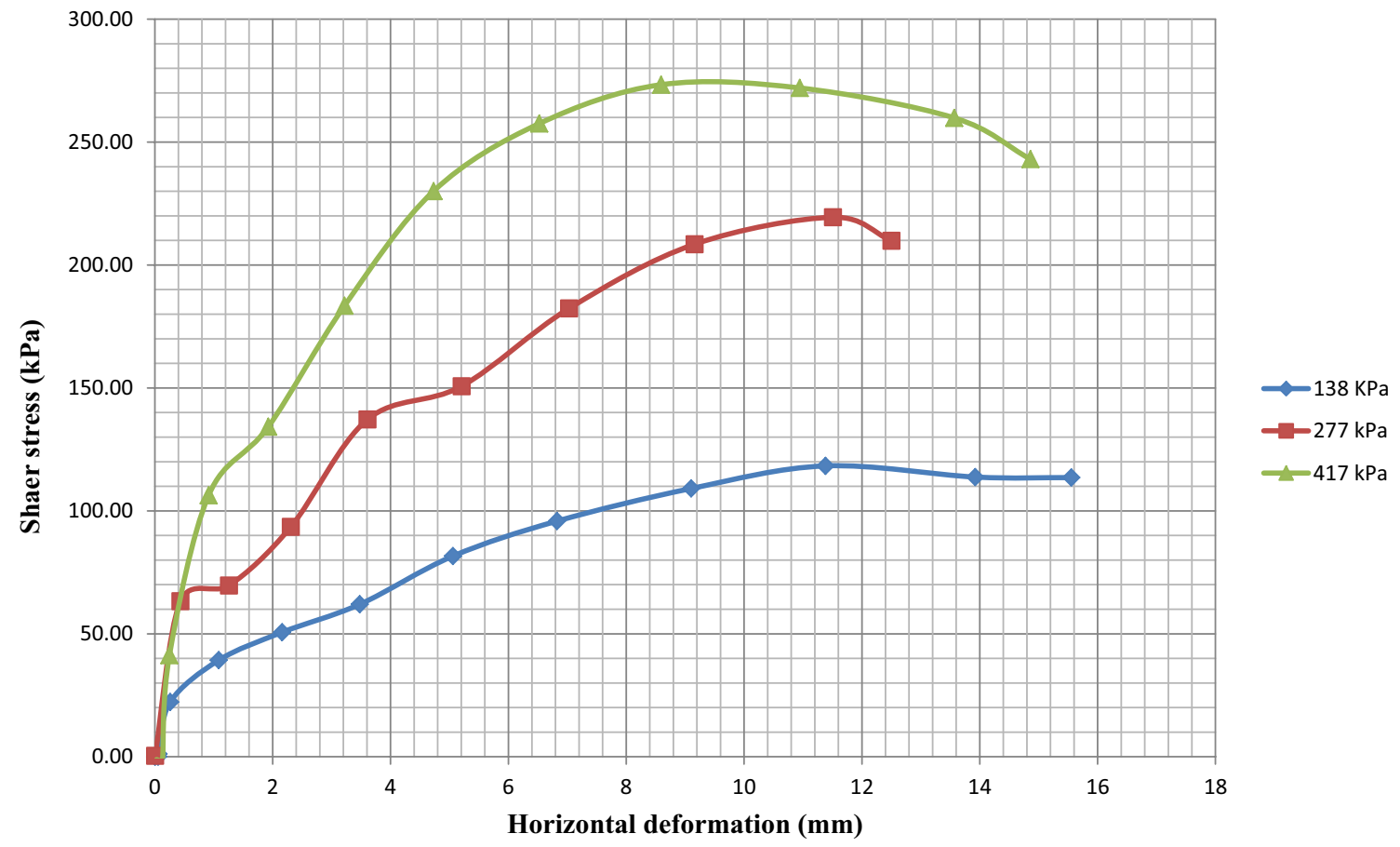

Fig. 4 Shear stress versus horizontal deformation curves for sample 'B'

\subsection{Elastic settlement values}

Three different equations, listed as Eqs. (1), (4), and (5) above were used in computing settlement. Table 7

SN Applied Sciences presents values of computed settlement and the parameters used.

Equation (1) gives values of settlement from 1.02 to $6.78 \mathrm{~cm}$, while Eq. (4) gives settlement values from 2.94 to 


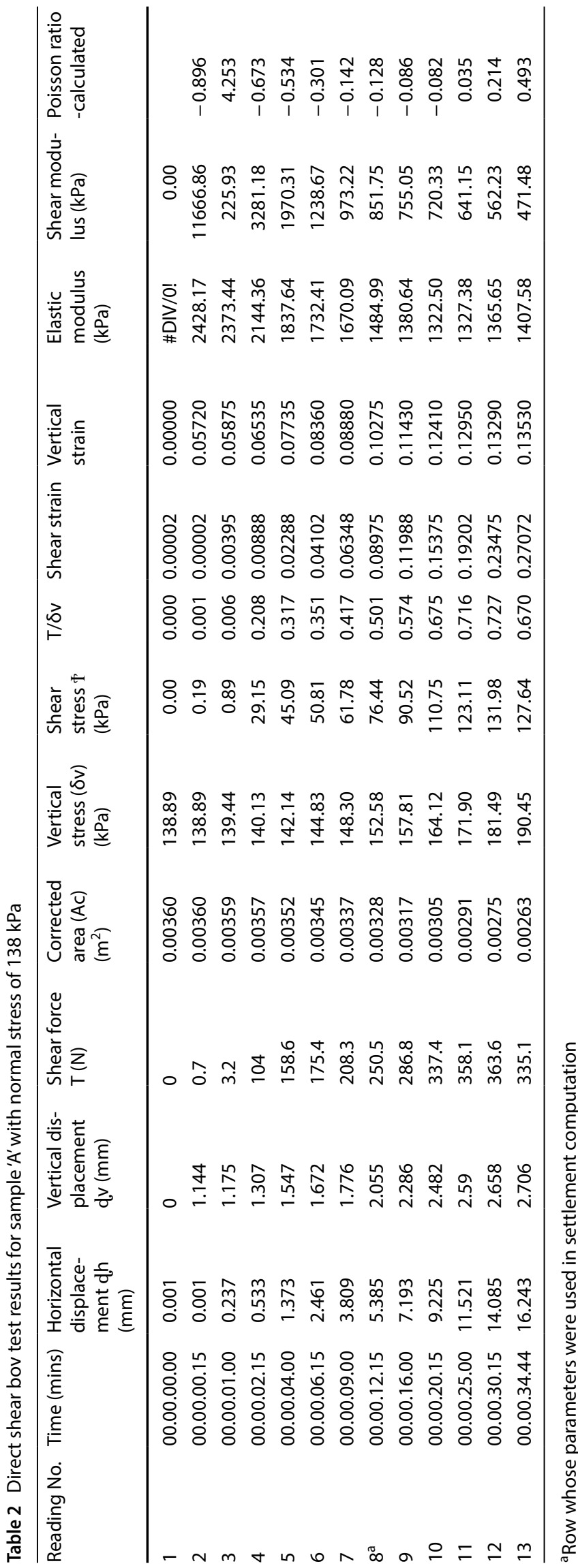

$12.65 \mathrm{~cm}$, values that are slightly more than twice those given by Eq. (1). Equation (4) assumes Poisson ratio of 0.15 , whereas Eq. (1) uses values of Poisson ratio existing in the soil at the stress state which is more realistic. The magnitude of settlement values are not dependent only on the magnitude of the ultimate bearing capacity or the allowable values. Sample 'D. has the largest ultimate bearing capacity of $688.93 \mathrm{kN} / \mathrm{m}^{2}$ and the allowable, yet it has the second least settlement values of $1.31 \mathrm{~cm}$, and $3.98 \mathrm{~cm}$ based on Eqs. (1), and (4) respectively. Furthermore, for all the settlement computations, settlement values are smaller with increasing Poisson ratio.

\subsection{Consolidation settlement values}

Equation (5) is usually used to compute consolidation settlement. The compressibility values $\left(m_{v}\right)$ in the equation is taken to be approximately equal to the inverse of the elastic modulus. From Table 7, its values ranges from 0.14 to 0.67 per $\mathrm{MPa}$, indicating 'medium' to 'high' compressibility based on [22] compressibility classification which is presented in Table 8. Consolidation settlement values are about $42 \mathrm{~cm}$ for the soil samples ' $A$ ' and ' $C$ ' which has high compressibility values of 0.67 and 0.49 respectively; whereas, samples ' $B$ ', ' $D$ ' and ' $E$ ' with $m_{v}$ values $0.14-0.24$, which represents medium compressibility values have settlement values from 9.76 to $21.45 \mathrm{~cm}$.

\subsection{Peak shear strength and computed allowable bearing capacity}

The allowable bearing capacity adopted from shear box tests are within the first and second sequence of normal load applied. The shear stress versus horizontal deformation plot (Figs. 3 and 4 being examples) indicate the allowable stress is developed in the soil when the soil consistency is 'loose' to 'medium dense'. Usually the first and second load sequence in this study and the shape of the associated curves indicate 'loose and 'medium dense' consistency $([23,24])$.The curves of $138 \mathrm{kPa}$ and that of $277 \mathrm{kPa}$ indicate for sandy soils, 'loose' and 'medium dense' respectively. The values indicated by the peak shear strengths for each of the relevant curves are reasonably close to the estimated allowable bearing stress. Samples 'A. ' $B$ ' ' $C$ ' $D$ ' and ' $E$ ' have computed allowable bearing stress values of $156.58 \mathrm{kPa}$, $220.51 \mathrm{kPa}, 214.92 \mathrm{kPa}, 229.64 \mathrm{kPa}$, and $138.54 \mathrm{kPa}$ respectively. The peak shear strengths for these samples from the plot of shear stress versus horizontal displacement curves respectively are $131.98 \mathrm{kPa}, 219.42 \mathrm{kPa}, 232.29 \mathrm{kPa}$, $257.4 \mathrm{kPa}$, and $129.29 \mathrm{kPa}$. Sample 'D' has the largest difference of $27.6 \mathrm{kPa}$ between the computed value and peak shear strength read from the plot, followed by Sample, ' $A$ ' with a difference in value of $24.6 \mathrm{kPa}$. 


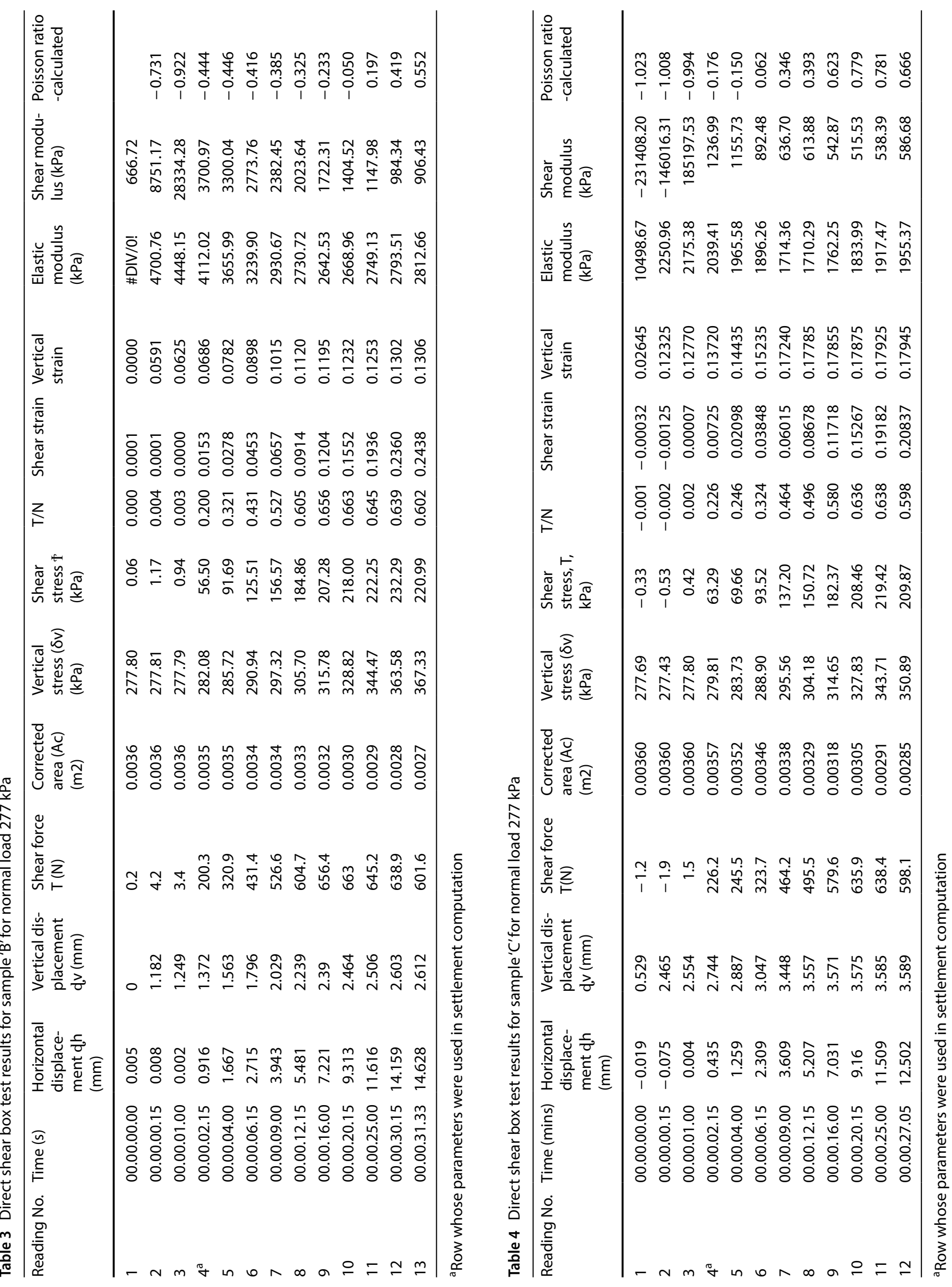




\subsection{Comparison of computed settlement values with those from previous works}

There is paucity of literature on examples of settlement either computed or observed of structures. Mayne [19] reported settlements of a raft footing for a 13 storey building of between $25 \mathrm{~cm}$ at the center of the structure to $12.7 \mathrm{~cm}$ at the corners. The raft size has a length of $104 \mathrm{~m}$, width of $18 \mathrm{~m}$, and thickness of $1.1 \mathrm{~m}$. The building was constructed on Piedmont residual silty soils. The soils are silty, and clayey, but have a clay fraction of less than $20 \%$. Load on the mat footing is estimated at about $150 \mathrm{kPa}$. Soil borings on the site investigated indicate the presence of sandy silts (ML), and silty sands (SM). Ground water table is at between 6.0 and $7.0 \mathrm{~m}$ below the ground surface. Settlement calculations were made using the equation provided by 'elastic continuum theory'. The equation is given as.

$\rho=(q)(d) I_{h} \frac{\left(1-v^{2}\right)}{E_{o}}$

where $\rho=$ is the settlement at the center of a footing, $\mathrm{Q}=$ the imposed load, $\mathrm{D}=$ width of the footing, $v=$ Poisson ratio taken to be between 0.1 and $0.2, E_{o}=$ equivalent elastic soil modulus beneath the foundation base determined for this case by Dilatometer, and $I_{h}=$ displacement influence factor that accounts for the simplified subsurface geometry, layering, foundation rigidity, layer thickness, and soil stiffness variation with depth obtained from chart prepared by [25].

The above equation was used to estimate settlements at different positions beneath the raft of the building ' $B$ ' reported in the article. The results matched the settlement observed. It was reported that consolidation tests overpredicts settlements on Piedmont soils, hence the adoption of the elastic continuum theory method. Compared to the study, the soils under investigation are essentially sand, although silty sand (SM) is common to the two cases. The loads used in estimating settlement in Piedmont soil which $150 \mathrm{kPa}$ is similar to that of sample ' $A$ ' in the present study. The consolidation settlements estimate for the soil in this study appears to be excessive for the particular load, although there is a paucity of data from the study area that will enable effective comparison. Applying Eq. (7) to calculate elastic settlement for the samples in this study, gives values that are higher than those computed with Eqs. (1) and (4). Settlements estimated by Eq. (1) seem more plausible.

Oweis and Scagnelli [26] reported on settlements of foundations for seven bridges that forms part of a $6.1 \mathrm{~km}$ Highway by-pass Route 31 Section $1 \mathrm{~A}$ project. Site investigation was carried out at the piers, and east and west abutment locations of the bridges.
The foundations were founded on overconsolidated clays which have silty sand (SM), poorly graded sands (SP), and SP-SM as intercalating layers. The clays include inorganic clay $(\mathrm{CL})$, inorganic silt of low to medium plasticity $(\mathrm{ML})$, inorganic silt of high plasticity $(\mathrm{MH})$, Inorganic clay $(\mathrm{CH})$, and $\mathrm{CL}-\mathrm{ML}$

Field investigation tools consist of Standard penetration test borings, piezocone soundings, and Pressuremeter testing. Settlement of the bridge structures was monitored from between 300 and 500 days after construction. Settlement estimation was made using the software, SETTLE/G (1987). It was reported that both immediate and consolidation settlements were calculated. Typical contact pressures on the center piers were about $123.8 \mathrm{kPa}$ while that of the abutment is about $264.9 \mathrm{kPa}$. All the foundations were spread footings. At bridge 1 , and at a boring designated No C1-1, a silty sand (SM) occurred at $3.66 \mathrm{~m}$ from the ground surface. Its Pressuremeter modulus was listed as $1.41 \mathrm{MPa}$. An average of four moduli was the modulus used in the settlement computations. The moduli are Pressuremeter modulus, unconfined compression modulus, Odoemeter modulus, and undrained triaxial compression tests with pore pressure measurements modulus. In this example, though triaxial tests represent one of the tests used to estimate modulus, it must be that it cannot give a value of Poisson ratio reliable enough to be employed in the computation of settlements; hence, a value of 0.33 was assumed. This could have effect on all the values of settlements computed. The method proposed by the present study estimate Poisson ratio reasonably.

It was reported that while the settlements for all the piers were over-predicted, the predictions for the abutment settlements were in accord with predictions except for one bridge. The East abutment of bridge 3 has an imposed pressure of $232.7 \mathrm{kPa}$, with average estimated elastic settlement of $2.70 \mathrm{~cm}$, and a total estimated settlement of $7.46 \mathrm{~cm}$. while average measured settlement is $5.95 \mathrm{~cm}$. In this study, the nearest load to the above is that of sample ' $\mathrm{D}$ ' which is $229.64 \mathrm{kPa}$. The least value of elastic settlement computed for this load is $1.31 \mathrm{~cm}$ while consolidation settlement is $13.29 \mathrm{~cm}$. Expectedly the elastic settlement values is less than that quoted for bridge 3 above since the soil here is sandy with some clays. No purely clayey or silty layer is assumed to be within the $4.0 \mathrm{~m}$ compressible stratum used in calculation in this study. Pure clay or silt will deform more than a sandy soil.

Dafalla [27] reports on settlements associated with soil which is similar both in type and geology to the one in this study. The study area is on the south west coast of Saudi Arabia, along the Red Sea coast (Coastal Plain Sands). The site is reported to be underlain by medium dense silty sand followed by very loose to medium dense silty sand to sandy silt; with Standard penetration test blow count as low as 4 

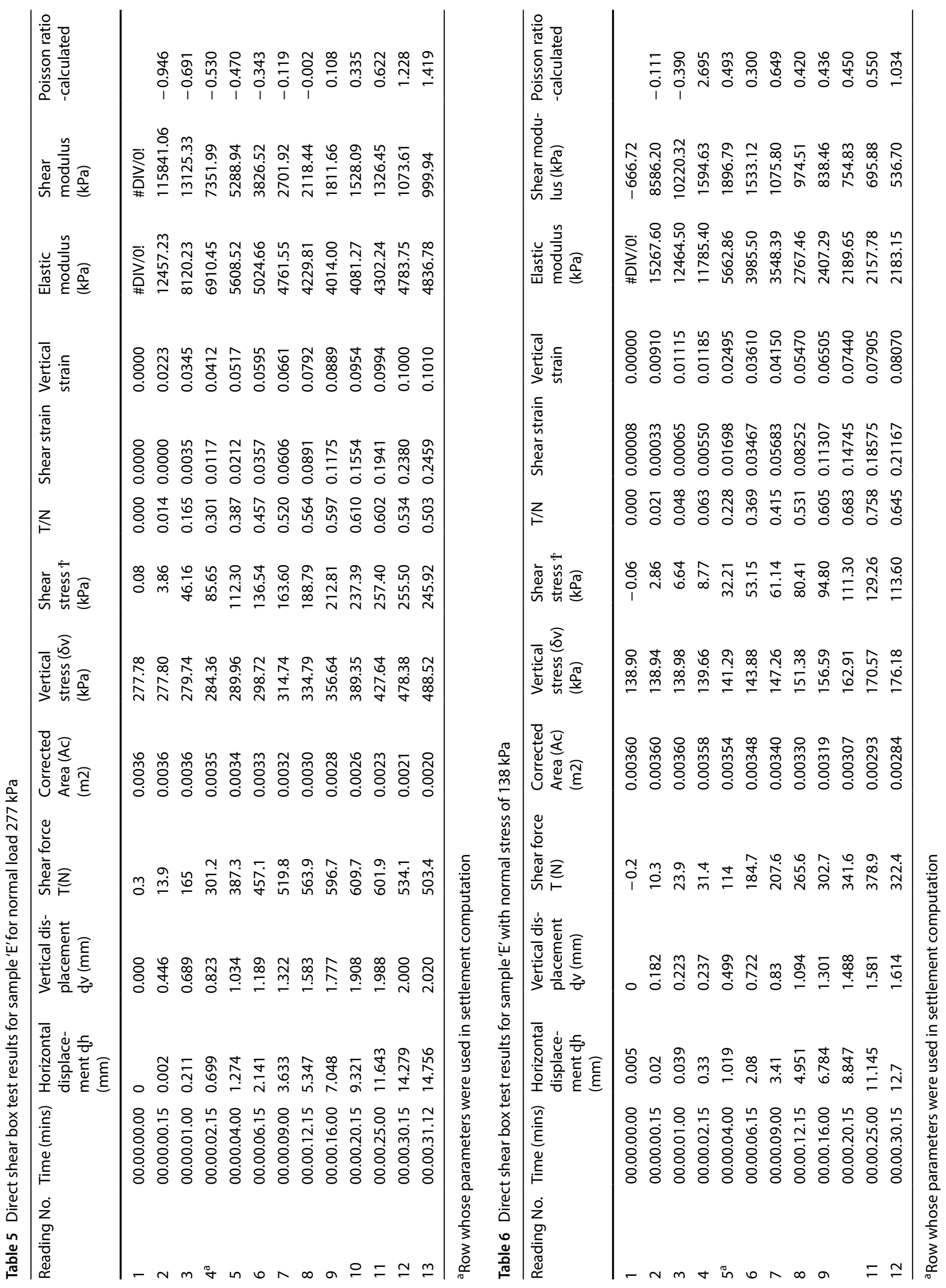


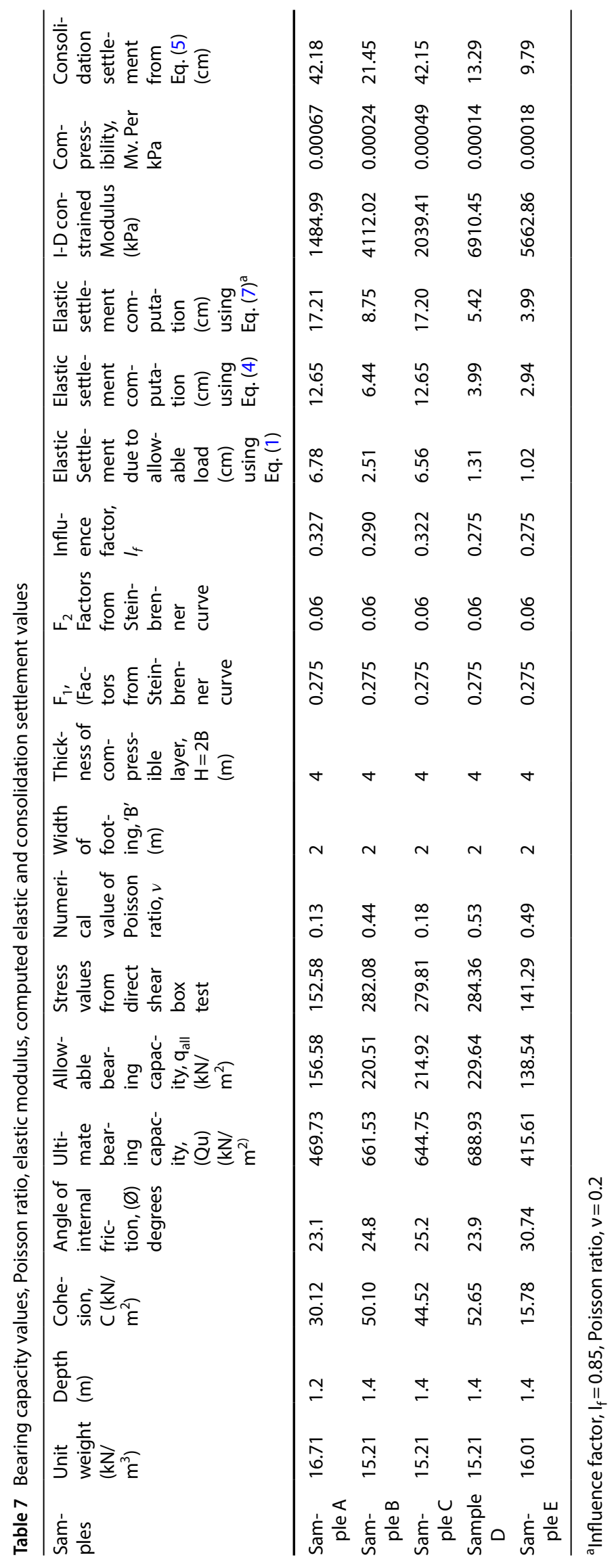


Table 8 Typical values of compressibility for clays ${ }^{a}$

\begin{tabular}{llll}
\hline Soil description & Compressibility & $\mathrm{M}_{\mathrm{v}}\left(\mathrm{m}^{2} \mathrm{MN}\right)^{-1}$ & $\mathrm{Cc}$ \\
\hline Heavily over consolidated clays & very low & $<0.05$ & $<0.10$ \\
Very stiff to hard clays & Low & $0.05-0.10$ & $0.10-0.25$ \\
Medium clays & Medium & $0.10-0.30$ & $0.25-0.80$ \\
Normally consolidated clays & High & $0.30-1.5$ & $0.80-2.50$ \\
Very organic clays and peats & very high & $>1.5$ & $>2.50$ \\
\hline
\end{tabular}

$M_{v}=$ Coefficient of volume compressibility; $C c=$ Coefficient of compression

${ }^{a}$ By D. G. McKinlay [22] blows per $300 \mathrm{~mm}$. Groundwater table is at $2.4-3.8 \mathrm{~m}$ below the ground surface. The materials are predominantly classified as SM, ML and SC. Clayey materials are very limited and are encountered as thin films. The soils are reported to be very compressible and liquefiable. Buildings for a technical college were planned for the site. To minimize settlement to tolerable limits, it was decided to preload the soil with sand embankment as surcharge, which will impose a minimum load of $100 \mathrm{kN} / \mathrm{m}^{2}$. The preloading was carried out for a total of 32 weeks. A settlement rate of $2.5-5 \mathrm{~cm} /$ week was observed during first 4 weeks, followed by a rate $0.25-0.5 \mathrm{~cm} /$ week from 4 to 12 weeks, and a very slow rate of settlement of $0.1-0.25 \mathrm{~cm} /$ week in the last $12-32$ weeks. This gives a total settlement in the range of $14-29 \mathrm{~cm}$ over the 32 weeks. With regard to the present study, the nearest load value close to the applied surcharge load is sample ' $E$ ' with a load of $141.29 \mathrm{kPa}$, which gives a total settlement of $10.81 \mathrm{~cm}$ by Eq. (1) and $12.73 \mathrm{~cm}$ by Eq. (4). These values are not significantly different from the lower value of the settlement observed in this example which is $12 \mathrm{~cm}$. It was also reported that changes occur within the 3-4 $\mathrm{m}$ from the ground surface, which represents approximately the thickness of compressible layer assumed in using Eqs. (1) and (4). This study however did not predict an upper limit of $29 \mathrm{~cm}$ observed settlement.

\subsection{Limitations of the method and future work}

1. Sample disturbance, due to removal of overburden pressure, which causes the top of the soil sample to expand.

2. The fact that the bearing capacity is not known when the Direct shear test is carried out may result in normal stress applied to sample being out of range. To address this, the usual doubling of the vertical load on the sample during Direct shear box test should not be used. Instead a stepwise increase in the vertical load should be adopted. For example, $100 \mathrm{~N}, 200 \mathrm{~N}, 300 \mathrm{~N}$, $400 \mathrm{~N}, 500 \mathrm{~N}$.... to $1500 \mathrm{~N}$. This loading sequence also depends on the type of soil being investigated. The loading sequence suggested will be appropriate for the type of soil investigated in this study, which are clayey and silty sands of medium to high compressibility.

The method hold good prospect for estimating settlement as noted in the first two cases cited where the Poisson ratio used for estimating settlements were assumed, whereas it is determined with this method.

\section{Conclusion}

A method using the Direct shear box test is put forward. It has been demonstrated that it is possible to obtain reasonable estimates of parameters that are required to estimate elastic settlement for the type of soil investigated in this study. Such parameters include, shear modulus, elastic modulus, and Poisson ratio.

Elastic settlement estimated using these parameters is realistic and reasonable for the type of soil.

Elastic settlement computed using basic elastic theory equation (Eq. 1) gave values that are least conservative compared to other equations used, but are plausible.

There is the possibility of deducing allowable bearing capacity of a soil by reading off the value of the peak shear resistance from the shear stress versus horizontal displacement curve of the loading sequence which develops the vertical stress close to the estimated value, which is the first and second load sequence in this study.

The modulus used in computing the settlements in this study was not adjusted as is normally done for the ones obtained from odoemeter test as the modulus is partially constrained while that of odoemeter is fully constrained.

Acknowledgements I wish to acknowledge and appreciate Robin Williams, Administrative Assistant at Grant African Methodist Episcopal Church in Toronto, Ontario, Canada, who helped with the proof reading of the revised article after the peer review. 


\section{Compliance with ethical standards}

Conflict of interest On behalf of all authors, the corresponding author states that there is no conflict of interest.

\section{References}

1. Begemann HKS (1974) General report for Central and Western Europe. In: Proceedings European symposium penetration test. Stockholm

2. Kulhawy FH, Mayne PW (1990) Manual on estimating soil properties for foundation design. Electric Power Research Institute, Palo Alto

3. Lunne T, Christoffersen HP (1985) Interpretation of cone penetrometer data for offshore sands, Norwegian Geotechnical Institute, Pub. No. 156

4. Menard L (1956) An apparatus for measuring the strength of soils in place. Master's Thesis, University of Illinois, Urbana, Illinois

5. ASTM D4719-07 (2007) Standard test methods for prebored pressuremeter testing in soils (Withdrawn 2016). ASTM International, West Conshohocken

6. Marchetti S (1980) In situ test by flat dilatometer. J Geotech Eng Div ASCE 106(GT3):299-321

7. Schmertmann JH (1975) Measurement of in situ shear strength. Proc Spec Conf In Situ Meas Soil Prop ASCE 2:57-138

8. Park CB, Miller RD, Xia J (1996) Multi-channel analysis of surface waves using Vibroseis. In: Expanded abstracts: 66th annual international meeting, society of exploration geophysicists, pp 68-71

9. Park CB, Miller RD, Xia J (1999) Multi-channel analysis of surface waves (MASW). Geophysics 64(3):800-808

10. ASTM D3080 / D3080M-11, Standard test method for direct shear test of soils under consolidated drained conditions, ASTM International, West Conshohocken, PA, 2011, www.astm.org. 18 $\mathrm{p}$

11. Ilori AO, Udoh NE, Umenge Jl (2017) Determination of soil shear properties on a soil to concrete interface using a direct shear box apparatus. Int J Geo-Eng 8:17. https://doi.org/10.1186/ s40703-017-0055-x

12. Berardi R, Lancellotta $R$ (1991) Stiffness of granular soil from field performance. Geotechnique 41(1):149-157

13. Berardi R, Jamiolkowski M, Lancellotta R (1991). "Settlement of shallow foundations in sand: selection of stiffness of the basis of penetration resistance." Geotechnical Engineering Congress, Geotech. Special Pub. 27, ASCE, pp 185-200
14. Tsytovich NA (1951) Soil mechanics. In: Stroitielstvo i Archiketura (ed) Moscow (in Russian)

15. Das B, Sivakugan N (2007) Settlements of shallow foundations on granular soil an overview. Int J Geotech Eng 1(1):19-29

16. Steinbrenner W (1934) Tafeln zur Setzungsberechnung. Die Strasse 1:121-124

17. Terzaghi K, Peck RB (1948) Soil mechanics in engineering practice. Wiley, New York

18. Poulos HG (2018) Estimation of geotechnical deformation parameters from small-strain shear modulus, in innovations in geotechnical engineering. In: Zhang X, Cosentino PJ, Hussein $\mathrm{MH}$ (eds) Proceedings of the international foundations congress and equipment expo. https://doi.org/10.1061/9780784481 639.004

19. Mayne PW (2005) Unexpected but foreseeable mat settlements on Piedmont residuum. Int J Geoeng Case Hist 1(1):5-17

20. Tatsuoka F, Teachavorasinskun S, Dong J, Kohata Y, Sato T (1994) Importance of measuring local strains incyclic triaxial tests on granular materials. Dynamic geotechnical testing II, STP 1213. ASTM, WestConshohocken, pp 288-302

21. LoPresti DCF, Pallara O, Puci I (1995) A modified commercial triaxial testing system for small strain measurements. ASTM Geotech Test J 18(1):15-31

22. McKinlay DG (1996) Soils. In: Jackson N, Dhir RK (eds) Civil engineering materials, 4th edn. Macmillan Education Ltd, Hampshire, pp 326-340

23. Das BM (2006) Principles of geotechnical engineering, 5th edn. Thomson, Stamford, p 317

24. Peck RB, Hanson WE, Thornburn TH (1974) Foundation engineering, 2nd edn. Wiley, New York, p 279

25. Mayne PW, Poulos HG (1999) Approximate displacement influence factors for elastic shallow foundations. ASCE J Geotech Geoenviron Eng 125(6):453-460. https://doi.org/10.1061/ (ASCE) 1090-0241(1999)125:6(453)

26. Oweis IS, Scagnelli P (2001) Bridge foundations for Hightstown bypass. J Geotech Geoenviron Eng 127:997-1016. https://doi. org/10.1061/(ASCE)1090-0241(2001)127:12(997)

27. Dafalla MA (2009) Improvement of coastal silty sand of Saudi Arabia using preloading technique. In: ASCE GeoHunan international conference. Material design, construction, maintenance, and testing of pavements. https://doi.org/10.1061/41045 (352) 16

Publisher's Note Springer Nature remains neutral with regard to jurisdictional claims in published maps and institutional affiliations. 